\title{
Maternal psychological control and preschool children's behavioral outcomes in China, Russia, and the United States
}

\author{
Susanne Frost Olsen \\ Chongming Yang \\ Craig H. Hart \\ Clyde C. Robinson \\ Peixia Wu \\ Follow this and additional works at: https://scholarsarchive.byu.edu/facpub
}

Phroxtofabe CothadditicialáadtBohavioral Sciences Commons

\section{Original Publication Citation}

Olsen, S. F., Yang, C., Hart, C. H., Robinson, C. C., Wu, P., Nelson, D. A.,Nelson, L. J., Jin, S., \& Wo, J. (2002). Maternal psychological control and preschool children's behavioral outcomes in China, Russia, and the United States. In B. K. Barber (Ed.), Intrusive parenting: How psychological control affects children and adolescents(pp. 235-262). Washington, D.C.: American Psychological Association (APA) Books.

\section{BYU ScholarsArchive Citation}

Olsen, Susanne Frost; Yang, Chongming; Hart, Craig H.; Robinson, Clyde C.; Wu, Peixia; Nelson, David A.; Nelson, Larry J.; Jin, Shenghua; and Wo, Jianzhong, "Maternal psychological control and preschool children's behavioral outcomes in China, Russia, and the United States" (2002). Faculty Publications. 4573.

https://scholarsarchive.byu.edu/facpub/4573

This Book Chapter is brought to you for free and open access by BYU ScholarsArchive. It has been accepted for inclusion in Faculty Publications by an authorized administrator of BYU ScholarsArchive. For more information, please contact ellen_amatangelo@byu.edu. 


\section{Authors}

Susanne Frost Olsen, Chongming Yang, Craig H. Hart, Clyde C. Robinson, Peixia Wu, David A. Nelson, Larry J. Nelson, Shenghua Jin, and Jianzhong Wo 


\title{
8
}

\section{MATERNAL PSYCHOLOGICAL CONTROL AND PRESCHOOL CHILDREN'S BEHAVIORAL OUTCOMES IN CHINA, RUSSIA, AND THE UNITED STATES}

\author{
SUSANNE FROST OLSEN, CHONGMING YANG, CRAIG H. HART, \\ CLYDE C. ROBINSON, PEIXIA WU, DAVID A. NELSON, \\ LARRY J. NELSON, SHENGHUA JIN, AND JIANZHONG WO
}

\begin{abstract}
A growing body of Western literature has demonstrated the importance of three domains of socialization-connection with significant others, regulation of behavior, and the facilitation of psychological autonomy-in predicting outcomes in adolescents and children (Barber, 1997a, 1997b; Gray \& Steinberg, 1999; Hart, Newell, \& Olsen, in press; Nelson, 1997; Steinberg, Dornbusch, \& Brown, 1992). Psychological control-parenting that does not allow children psychological autonomy, as has been defined elsewhere in this volume, has received increased attention in the past decade (for a discussion of definitions and research, see chapter 2, this volume).

Most of the earlier work regarding psychological control has focused on adolescents. The construct has been viewed as being more relevant to them than other age groups because adolescents strive to establish a sense of identity and transform their relationships with families and peers. It has been hypothesized, however, that the psychological control construct may be useful across the life course if it is conceptualized broadly as intrusion
\end{abstract}

\footnotetext{
We express our appreciation to the parents and teachers who participated in this study, as well as to Dr. Nina Bazarskaya, head of the Foreign Language Department, Voronezh Forestry Institute, Voronezh, Russia, for her assistance in providing access to the Russian sample. Support for this research was provided by the Kennedy Center for International Studies, the College of Family, Home and Social Sciences, the Camilla Eyring Kimball Endowment, and the Family Studies Center at Brigham Young University. We are also grateful to Dr. Joseph Olsen for his statistical consultation.
} 
into the child's self-expression. Intrusion and violation of psychological autonomy may occur, even in children who are very young (Barber, 1996; see also chapter 2 , this volume). Recent research indicates that components of psychological control may be linked to negative outcomes for schoolage children (Grotpeter, 1997; Mills \& Rubin, 1998; Nelson, 1997; Shulman, Collins, \& Dital, 1993), preschoolers (Gottman, Katz, \& Hooven, 1997; Olsen, Wells, Hart, \& Robinson, 2000; Wells, 1998), as well as younger children (Crockenberg \& Litman, 1990).

Another limitation in previous work is that the majority of studies, with a few exceptions, have been conducted in the United States. As a result, research is only beginning to appear regarding the link between psychological control and child outcomes in cross-cultural settings (see chapter 2, this volume; for exceptions, see Hart, Nelson, Robinson, Olsen, \& McNeilly-Choque, 1998). Steinberg, Mounts, Lamborn, and Dornbusch (1991) supported this type of research, recommending that more studies should attend to "process-by-context interactions," or the investigation of "the ways in which developmental processes vary as a function of the broader context in which they occur" (p. 20).

The purpose of our research is two-fold. Our first aim is to expand the study of psychological control and its related outcomes into the realm of younger children, specifically examining preschoolers. Our second purpose is to investigate these relations in three cultures, the United States, China, and Russia. We included three cultures, as recommended by Segal, Lonner, and Berry (1998), to make meaningful and interpretable cross-cultural comparisons.

\section{PSYCHOLOGICAL CONTROL AND CHILDREN'S INTERNALIZING AND EXTERNALIZING BEHAVIOR}

As mentioned previously, the relationship between psychological control and adolescents' problem behaviors has been documented in research literature for the past decade (e.g., Barber, 1996; Barber, Olsen, \& Shagle, 1994; Gray \& Steinberg, 1999; Steinberg, Elmen, \& Mounts, 1989). A major focus of this research has been directed toward distinguishing between psychological control and behavioral control and how these constructs differentially relate to adolescent development (for distinctions between psychological control and behavioral control, see Steinberg, 1990; chapters 1 and 4 , this volume).

In the literature regarding younger children, psychological control or some of its components (i.e., guilt induction, love withdrawal, etc.) has only recently been linked to schoolage and preschool child outcomes (Gottman et al., 1997; Grotpeter, 1997; Hart, Nelson, et al., 1998; Mills \& Rubin, 1998; 
Nelson, 1997; Olsen et al., 2000; Shulman et al., 1993; Wells, 1998; see also chapters $5-7$, this volume). In the following section we briefly review research on psychological control and adolescents' internalizing and externalizing problems to provide a context for the research literature we review next regarding younger children.

\section{Internalizing Behavior}

In the adolescent literature, an extensive body of research has emerged supporting the relationship between psychological control and internalizing behavior. Studies have shown that psychological control is a significant predictor of internalizing problems, even after controlling for parenting variables such as connection and regulation or school and peer variables (Barber \& Olsen, 1997; Eccles, Early, Frasier, Belansky, \& McCarthy, 1997). These relationships have also been supported in longitudinal studies (see chapter 2, this volume).

In addition, preliminary findings of cross-cultural research conducted with adolescents in the United States, Colombia, Gaza, South Africa, India, and Australia indicate that psychological control is related to adolescent self-reported depression in these varied settings (chapter 2, this volume). In contrast, Bean (1997) found that after controlling for parental acceptance and monitoring, maternal and paternal psychological control was related to youth depression for African Americans but not for Hispanics in the United States.

Typically, work with adolescents has narrowly operationalized internalizing as including depression and psychological or somatic disorders; however, in studies of younger children internalizing behaviors have consisted of behaviors such as shyness, withdrawal, anxiety, sadness, loneliness, or poor self-esteem (e.g., Gresham \& Elliott, 1990; Hart, Olsen, Robinson, \& Mandleco, 1997). In addition, although much research with adolescents regarding psychological control has used Barber's (modified from Schaefer) conceptualization, research with young children has generally examined specific components of the psychological control construct (i.e., guilt induction, love withdrawal, etc.). Therefore, in reviewing the literature regarding young children, we must extrapolate in finding commonalities.

For example, Holden (1997) described "psychological maltreatment," which might be considered an extreme form of psychological control, as consisting of threatening to abandon the child and "ignoring the child's attempts and need for interaction" (p. 146). Baumrind (1966) also cautioned against manipulation of the love relationship as well as the use of guilt induction in relationships between parents and children. Besides these theoretical arguments, research has demonstrated possible linkages between components of psychological control and younger children's outcomes. 
A line of research by Rubin and colleagues (e.g., Rubin, Bukowski, \& Parker, 1998; Rubin, Nelson, Hastings, \& Asendorpf, 1999; Rubin, Stewart, $\&$ Chen, 1995) has shown that psychological overcontrol (operationalized as overprotectiveness, overinvolvement and constraints on exploration and independence in earlier research) is related to social withdrawal in younger children. In addition, in a recent study of children in kindergarten, second, and fourth grades, psychologically controlling behavior, operationally defined as involving threats to the child's self esteem, was used more by mothers of withdrawn (i.e., internalizing) children than by mothers of average children (Mills \& Rubin, 1998).

The literature indicates that children with severe internalizing problems such as neuroticism and anxiety disorders have family environments that include components of psychological control. For instance, descriptive research with younger children involving clinical records, case studies, and retrospective reports has characterized parents of children with neurotic or anxiety disorders as limiting their children's psychological autonomy by being invasive of their physical or psychological privacy (Siqueland, Kendall, \& Steinberg, 1996). Also, children with anxiety and depressive disorders have rated their families as more enmeshed (interpersonally overinvolved) than children without anxiety disorders (Stark, Humphrey, Crook, \& Lewis, 1990). Other researchers (Siqueland et al., 1996) found that observers rated parents of schoolage children with anxiety disorders as less granting of psychological autonomy than parents of children in the control group.

It has also been hypothesized that the use of love withdrawal may be related to anxiety (Maccoby \& Martin, 1983) and neurotic, inhibited behaviors in younger children (Hoffman, 1983; Putallaz \& Heflin, 1990). In addition, negative parental evaluative feedback, such as shaming of children, has been associated with preschoolers' expressions of being shamed, such as withdrawing from task situations or negative self-evaluations (Alessandri \& Lewis, 1993).

Only a few studies with children have specifically examined the psychological control construct. Morriss et al. (chapter 5, this volume) found that for children who were rated as irritable and distressed by their mothers, maternal psychological control, as assessed by the children, predicted teacher assessments of child internalizing. Supporting some of the findings with adolescents and schoolage children, research with preschoolers indicated that psychological control was correlated with parent-reported child internalizing problems only when mothers described their spouse's use of psychological control; no associations existed when fathers reported about their wives (Olsen et al., 2000; Wells, 1998).

In sum, the body of research regarding the relationship between psychological control and adolescent internalizing behavior is more well-developed and in general supports the theory. Although less research has been per- 
formed with samples of children in preschool and middle childhood, the theory also appears to be supported.

\section{Externalizing Behavior}

Although psychological control was originally associated with adolescent internalizing behaviors, subsequent research demonstrated that it is also related to adolescent externalizing problems, such as delinquency or antisocial behavior (see chapter 2 , this volume, for a review). Only a few studies, however, have investigated the linkage between psychological control and adolescent antisocial behavior with ethnically diverse samples or in cross-cultural settings. One example is Barber and Harmon (chapter 2, this volume), who found in cross-cultural research performed in the United States, Gaza, Colombia, South Africa, India, and Australia that psychological control was associated with adolescent antisocial behavior in all cultures.

Other research performed with Hispanics and African Americans in the United States has been less consistent. For example, Bean (1997) reported that maternal and paternal psychological control was unrelated to antisocial behavior for both Hispanics and African Americans. In contrast, in a longitudinal study of African American adolescents, maternal psychological control (measured somewhat differently than Barber's conceptualization) had a curvilinear relation with youth problem behaviors. When adolescents in the sample associated with problem peers, higher and lower levels of psychological control were related to higher levels of problem behaviors (Mason, Cauce, Gonzales, \& Hiraga, 1996).

The linkage between psychological control and externalizing behaviors may also be applicable to younger age groups. For example, research conducted with both adolescents and schoolage children revealed that psychological control was a more salient predictor of delinquency among fifthgrade students than eighth-grade students (Barber, 1996). In addition, one aspect of psychological control (e.g., love withdrawal) has also been associated with externalizing behavior, such as overt aggression, in schoolage children (Grotpeter, 1997). Morris et al. (chapter 5, this volume) also found that when mothers rated their schoolage sons' temperament as high on either fearful or irritable distress, psychological control was related to teachers' ratings of the boys' externalizing behaviors. These relations were not significant for girls, however.

Although there is less research regarding psychological control and its relationship with younger children's externalizing behavior, Rubin, Coplan, Nelson, Cheah, and Lace-Seguin (1999) reported that parents who are disapproving and critical of their children, while also being permissive, have children who tend to be more aggressive with their peers. Wells (1998) noted that although not described as psychological control in Rubin's writing, these 
seemingly contradictory behaviors (disapproving and permissive or punitive and permissive) may demonstrate a tendency for erratic emotional behavior (one aspect of psychological control) on the part of parents.

Research with preschool children in the United States found that correlations existed between parents' assessments of their spouse's use of psychological control and their reports of their own child's externalizing behavior (Olsen et al., 2000; Wells, 1998). In contrast, in a study of preschoolers in Russia, mothers' psychological control was linked to teacherreported overt aggression of boys and girls, but no association existed when fathers were reporting (Hart, Nelson, et al., 1998). In examining this data further, Hart, Nelson, et al. (2000) found preschool children whose mothers reported high levels of psychological control were rated as more overtly and proactively aggressive than children whose mothers reported low levels.

In sum, the patterns of findings regarding externalizing behavior are similar to those regarding internalizing. A larger and more highly developed body of research generally supports the hypothesis that psychological control is associated with adolescent externalizing; the extant literature for schoolage children and preschoolers is much less developed but indicates similar relationships.

\section{CHINESE AND RUSSIAN CULTURE AND PSYCHOLOGICAL CONTROL}

There is some evidence that differences may exist in cultural acceptance and parental use of psychological control. Parenting may vary across different ecologies because parents may have different goals, representing the cultural norms by which children are socialized (Darling \& Steinberg, 1993; Hart, Nelson, et al., 2000). Thus, although psychological control has been viewed as uniformly negative in the United States (Barber, 1996), it may be more frequently used, and therefore more acceptable, as a means of regulating young children's behavior in other cultures, particularly in China (Wu et al., 2000).

\section{China}

Confucian values and teachings are still evident in patterns of socialization among Chinese people today, although many were denounced during the early years of the People's Republic (Miller, Wiley, Fung, \& Liang, 1997; Wu, 1996, 1997). Even though Confucian values may permeate Chinese child-rearing, a number of authors (Bond, 1991; Ho, 1986, 1996) have proposed that there is no one predominant method of child socialization in Chinese society. 
In addition, the pattern of Chinese socialization often changes as a function of the child's age. For example, Chinese parents typically are lenient or indulgent in their attitudes toward infants and young children, which is very different from the stricter discipline that they impose on older children (Garcia Coll, Meyer, \& Brillon, 1995; Ho, 1986). Thus, following Confucian teachings, as soon as children are able to understand, obedience is more strongly emphasized (Wu, 1996). This change in attitude occurs when the child has reached the age of "understanding" or "reason," usually at around 4 to 6 years of age (Gorman, 1998; Ho, 1986).

In socializing their children, Ho (1986) reported that parents may use a variety of strategies, including threatening, scolding, punishing, and shaming. He emphasized, however, that these are not the only child-rearing methods being used. More recent empirical work (Chen, Dong, \& Zhou, 1997) documenting the use of authoritarian and more positive authoritative parenting styles in the Chinese culture supports the view that a variety of parenting styles are present, including some that may be viewed negatively in the Western literature (see Wu et al., 2000).

Among some of the "negative" parenting styles that might be used by Chinese parents, the literature does support the notion that some components of psychological control are used by Chinese parents in socializing their children. For example, research conducted in the 1970 s, reviewed by Ho (1986), indicated that compared to American mothers, Chinese mothers used more "love-oriented" methods of child-rearing, such as threat of withdrawal or actual withdrawal of love (a component of psychological control). Love withdrawal was used less frequently, however, than reasoning and induction. In addition, parents relied more on power assertion and love withdrawal when disciplining sons. Research conducted a decade later by Wu (1985) showed that many of the mothers who were interviewed reported that if a child misbehaved, she would scold him, ask him to apologize, and then "would assure the child that she would love him or her again as long as he or she was good" (p. 130).

More recent research (Fung, 1999) examined Chinese parents' beliefs and practices regarding shaming (another possible component of psychological control) and indicated that shaming was used to teach young children right from wrong. Shaming behaviors as measured by Fung ranged from explicit (where one of the persons made a specific reference to shame) to implicit. Although no single behavior defined shame, some "markers" of shaming included verbal techniques (name-calling, derogatory attributions, threats of abandonment, etc.), paralinguistic techniques (angry intonation, emphatic stress, etc.), as well as nonverbal techniques (displaying the shaming gesture, frowning, rolling the eyeballs, turning the whole body away from the child, etc.). Some of these behaviors (e.g., derogatory comments, threats of abandonment and turning away from the child) also seem akin 
to love withdrawal. For example, U.S. researchers (Rollins \& Thomas, 1979) have described love withdrawal as including ignoring, isolating the child, indications of rejection, disappointment, or coldness in response to something the child has done that displeases the parent.

Fung (1999) also noted that not only did parents shame their children, but primary schools in Taiwan, for example, used shaming (including group ostracism or abandonment) as a principal moral training technique (see Wilson, 1970, 1981). Teachers manipulated the shaming to correct children's misbehavior as well as underscore the class' disapproval and the appropriateness of other children's behavior (Fung, 1999; Ho, 1986). It should be noted, however, that in one study neither parents nor children named shaming as a method used if a child misbehaved (Stevenson, Chen, $\&$ Lee, 1992).

Thus, some aspects of psychological control, particularly shaming, love withdrawal (i.e., threats of abandonment), and guilt induction seem to be a prevalent part of Chinese children's socialization, both at home and in the school. Chen, Rubin, $\mathrm{Li}$, and $\mathrm{Li}$ (1996) pointed out that it is generally believed that awareness of shame may push a child to improve his or her performance. As a consequence, children who have behavioral or social problems may be humiliated, in private and in public, by parents, teachers, and peers.

\section{Russia}

Psychological control also may have been one means of parental and peer-group control encouraged in the Soviet Union when more positive types of socialization failed. For example, threat of ostracism from the group was one method used in the Russian educational system to encourage conformity to collectivistic ideals (Hart, Nelson, et al., 1998).

Bronfenbrenner (1970), writing about child-rearing in the former Soviet Union, described "love oriented" discipline as including love withdrawal (e.g., avoiding a child when she or he does not meet parental expectations) and guilt induction (e.g., telling a child that she or he may not be as good as other children). According to Bronfenbrenner, these two types of parenting "seem to apply rather well to patterns of child rearing in the Soviet family" (p. 71).

In addition, parenting patterns that provoke anxiety or guilt have also been reported to have been empirically measured in the Russian culture (Subbostskii, 1992). Research performed with adolescents in St. Petersburg demonstrated that parental granting of psychological autonomy was related to positive child outcomes such as self-reliance, but unrelated to antisocial behavior, substance abuse, and school misbehavior (Pallock \& Lamborn, 1997). Alternately, a study conducted in Voronezh, Russia, with preschool- 
age children revealed that psychological control was related to overt aggression (Hart, Nelson, et al., 1998).

Once again, it should be mentioned that although Russian parents may use elements of psychological control in rearing their children, other parenting styles are also used (e.g., Bronfenbrenner, 1970; Marenko, 1937). For example, recent work with Russian parents of preschoolers has shown that authoritative, authoritarian, and permissive parenting can be empirically measured (Hart, Nelson, et al., 2000).

Thus, it appears that psychological control is a parenting style that has been used by parents in the United States, Russia, and China. In light of the growing empirical evidence suggesting that psychological control predicts negative outcomes in diverse cultural settings, we hypothesize that psychological control will be related to teacher perceptions of internalizing and externalizing behavior in preschool children in all three cultures.

\section{THE STUDY}

Parents and teachers of 632 children from three cultural contexts, China, Russia, and the United States, participated in the study. Sample 1 included mothers of 194 children ( 95 boys; 99 girls) attending a university or community-based early childhood program in the Provo-Orem area in Utah (response rate approximately 60\%). Sample 2 consisted of mothers of 190 ethnic Russian children ( 88 boys; 102 girls) enrolled in 15 classrooms in three nursery schools in Voronezh, Russia (response rate above $75 \%$ ). Voronezh is a provincial city of one million located approximately 250 miles south of Moscow. Soviet officials strictly regulated foreign visitors until 1990, when outsiders obtained free access to the city. Even today, Voronezh is unusual because it is relatively isolated from Western influence because of its location. Sample 3 included mothers of 248 children ( 129 boys; 119 girls) attending one of four nursery schools in Beijing, China (response rate over $80 \%$ ). Beijing, with a population of approximately 10 million people, is the capital and cultural center of China.

Demographic statistics from the three samples, based on maternal reports, are presented in Table 8-1. Parents in all samples were relatively well-educated and were in their 30s. As expected, children in China had no siblings, as a result of the one-child policy. Russian families were smaller, compared to those living in Utah, where larger families are more the norm.

Data were gathered from parents and teachers in Utah, China, and Russia. Before collecting data, parental consent was obtained for all aspects of the study for the Utah sample. Russian and Chinese nursery schools act in loco parentis (in place of the parents), and as a result researchers were not allowed to obtain written parental permission. However, in group meetings 
TABLE 8-1

Demographic Information for Samples from China, Russia, and the United States

\begin{tabular}{|c|c|c|c|c|c|c|c|c|c|}
\hline & \multicolumn{3}{|c|}{ China } & \multicolumn{3}{|c|}{ Russia } & \multicolumn{3}{|c|}{ USA } \\
\hline & $M$ & SD & Range & $M$ & $S D$ & Range & $M$ & $S D$ & Range \\
\hline $\begin{array}{l}\text { Child age } \\
\text { (months) }\end{array}$ & 60.40 & 7.82 & 40 to 76 & 60.68 & 8.52 & 44 to 79 & 56.36 & 5.32 & 38 to 68 \\
\hline $\begin{array}{l}\text { Mother's age } \\
\text { (years) }\end{array}$ & 32.60 & 2.92 & 26 to 43 & 30.52 & 5.34 & 21 to 45 & 30.17 & 4.13 & 20 to 55 \\
\hline $\begin{array}{c}\text { Father's age } \\
\text { (years) }\end{array}$ & 34.95 & 3.53 & 28 to 52 & 32.40 & 7.09 & 22 to 62 & 32.53 & 5.85 & 21 to 53 \\
\hline $\begin{array}{l}\text { Mother's } \\
\text { education } \\
\text { (in years) }\end{array}$ & 13.39 & 2.40 & 5 to 20 & 14.88 & 2.37 & 9 to 17 & 13.84 & 1.93 & 9 to 20 \\
\hline $\begin{array}{l}\text { Father's } \\
\text { education } \\
\text { (in years) }\end{array}$ & 13.93 & 2.65 & 7 to 22 & 14.49 & 2.41 & 9 to 17 & 14.43 & 2.55 & 6 to 24 \\
\hline $\begin{array}{l}\text { Children in } \\
\text { family }\end{array}$ & 1 & 0 & 1 & 1.33 & .54 & 1 to 5 & 2.95 & 1.5 & 1 to 8 \\
\hline
\end{tabular}

arranged by school administrators, parents were informed about the study, allowed to ask questions concerning the research, assured of the confidentiality of individual and parenting data that they or a teacher provided, and advised that they or their children could withdraw from voluntary participation at any time.

In Utah, parents individually completed the psychological control questionnaire in their homes. Researchers or teachers delivered the measures. In Russia and China, parents first attended an initial meeting held at the preschool. Chinese parents completed the psychological control questionnaire while at the preschool, and a member of the research team was available to respond to questions. After the initial meeting, Russian parents took questionnaires home to complete. In all cultures parents were asked not to consult with each other while completing the instruments. Questionnaires regarding children's externalizing and internalizing behavior were delivered to teachers in their classrooms in all three cultures. Teachers completed questionnaires at the preschool after school hours.

As we have discussed elsewhere (Hart, Nelson, et al., 1998; Hart, Yang, et al., 2000), a number of methodological issues are inherent in crosscultural research, including the use of emic (arising from the culture) versus etic (comparison of similarities across cultures) approaches (Berry, 1989). Based on the literature reviewed and our experiences in the three cultures, we have hypothesized that there is functional equivalence in the psychological control, internalizing, and externalizing constructs being examined; that is, 
they seem to carry similar meanings and are "recurrent" in all three cultural settings (Berry, 1989).

Even though components of psychological control may be "recurrent" and "recognizable" in diverse cultural settings, there may be cultural nuances in the perceived meaning of the behaviors. For example, although psychological control may be equally identifiable in different cultures, it may be more prevalent in the Chinese and Russian cultures (Hart, Nelson, et al., 2000; Triandis, 1994; Wu et al., 2000). To examine this possibility, cultural comparative analyses were conducted to assess possible mean level differences or similarities in perceptions of psychological control.

Operating on the assumption that we do not have "imposed etics" (imposition of concepts originating in U.S. culture on other cultures), it is acceptable to use instruments that are conceptually equivalent, or in other words similarly understood by persons in the three cultures, even though they may carry somewhat different psychological meanings. Thus, items reflecting psychological control should be similarly understood by parents in U.S., Chinese, and Russian settings. Questionnaires were forward and back-translated to operationalize this, as well as to demonstrate translation equivalence.

We also wanted to examine whether results from the three cultures could be fit by a common statistical model. Metric equivalence exists when the psychometric properties of data from two or more cultures have similar factor structures (Hart, Yang, et al., 2000). Invariance of factor loadings across cultural groups are essential in cross-cultural studies (Little, 1997; Widaman \& Reise, 1997).

All instruments were forward and back-translated by Chinese and Russian linguists who were fluent in both English and their native languages. Researchers were consulted on difficult to translate items. Back-translated items were comparable with the English version.

Parents in all three cultures completed a psychological control questionnaire that was an adaptation of Barber's (1996) measure, in which adolescents report on their parents' use of psychological control. Because our sample was made up of preschool children, the questionnaire was adjusted so that parents could fill out a self-report concerning their own parenting. A team of early childhood experts also added items to better reflect this construct for parents of preschoolers. This modification resulted in an item pool consisting of 16 items previously used by Barber and 17 additional items (Table 8-2). Items were designed to tap dimensions of psychological control and included constraining verbal expression, invalidating feelings, personal attack, erratic emotional behavior, love withdrawal, and guilt induction. Guilt induction, love withdrawal, and erratic emotional behavior were overrepresented in the item bank because of earlier research suggesting these constructs are often used with younger children (Eisenberg \& Murphy, 
Psychological Control Item Bank

Constraining Verbal Expressions

(Bar) Changes the subject whenever our child has something to say.

(Bar) Interrupts our child when he/she is speaking.

(Bar) Finishes our child's sentence whenever he/she talks.

\section{Invalidating Feelings}

(Bar) Tries to change how our child feels or thinks about things.

(Bar) Acts like he/she knows what out child is thinking or feeling.

(Bar) Would like to tell our child how to feel or think about things.

\section{Personal Attack}

(Bar) Brings up our child's past mistakes when criticizing him/her.

(Bar) Tells our child that his or her hehavior was dumb or stupid.

(Bar) Blames our child for other family member's problems.

\section{Erratic Emotional Behavior}

(New) Shows impatience with our child.

(New) Shows erratic emotional behavior around child.

(Bar) Goes back and forth between being warm and critical toward our child.

(New) Doesn't like to be bothered by our child.

(Bar) Changes moods when with our child.

(New) Loses temper easily with our child.

\section{Love Withdrawal}

(Sch) Will avoid looking at our child when our child has disappointed him/me.

(New) Ignores our child when he/she tries to get attention.

(Sc) If our child has hurt our feelings, stops talking to our child until the child pleases him/me.

(Sch) Is less friendly with our child if our child does not see things his/my way.

(New) Doesn't pay attention when our child is speaking to us.

\section{Guilt Induction}

(Block) Lets our child know when he/she has disappointed him/me.

(New) Tells our child he/she is not as good as we were growing up.

(Block) Lets our child know when we are angry with him/her.

(Block) Makes our child aware of how much we sacrifice or do for him/her.

(Sch) Says, if you really care for me, you would not do things that cause me to worry.

(Sch) Tells our child of all the things he/l have done for him/her.

(New) Acts disappointed when our child misbehaves.

(New) Tells our child that he/she should be ashamed when he/she misbehaves.

(New) Tells our child that we get embarrassed when he/she does not meet our expectations.

(New) Makes our child feel quilty when our child does not meet our expectations.

(Block) Informs our child that punishment will always find him/her when misbehavior occurs.

(Block) Lets our child know how disappointed we are when he/she misbehaves.

(Bar) Tells our child he/she is not as good as other children.

Note: Sch = Schaefer items used by Barber (1996); Bar = Barber items; New = new items developed by early childhood experts; Block $=$ Block items. 
1995; Hoffman, 1983). Parents rated their parenting behavior on the 33 Likert-scaled items anchored from (1) never to (5) always.

Preschool teachers in all three cultures rated children's internalizing and externalizing behaviors. Items used in this study have been included in measures successfully used with teachers of preschoolers in North American samples (Hart, Yang, et al., 1998; McNeilly-Choque, Hart, Robinson, Nelson, \& Olsen, 1996; Nelson, Hart, Robinson, \& Olsen, 1997) and were deemed by early childhood experts to be the most easily observed by preschool teachers in all three cultures. As described earlier, all items were forward-translated and then successfully back-translated by Russian and Chinese linguists. The items assessing internalizing and externalizing behaviors used a rating based on frequency or "how often" a social behavior occurs: (0) never, (1) sometimes, or (2) very often.

Traditionally, externalizing outcomes have been described as inappropriate, undercontrolled behaviors including verbal or physical aggression toward others, arguing, poor control of temper, or impulsive-disruptive and nonconforming behaviors (e.g., Gresham \& Elliott, 1990; Hart et al., 1997). The five items used in this research reflect aggressive-disruptive behaviors that might be similarly identified by preschool teachers in the three cultures and included "becomes aggressive when rough housing with peers," "blames others," "disturbs ongoing activities," "is aggressive towards people or objects," and "gets into fights."

Internalizing outcomes have been defined as behaviors indicating shyness, withdrawal, anxiety, sadness, loneliness, or poor self-esteem (e.g., Gresham \& Elliott, 1990; Hart et al., 1997). Internalizing items used in this research also consist of behaviors that preschool teachers could easily observe in all three cultures, and included "acts unhappy," "says nobody likes him or her," "pouts and sulks," and "appears lonely."

\section{FITTING BARBER'S MODEL TO THE STUDY DATA}

Initially, we used structural equation modeling (SEM) procedures (Arbuckle, 1997) to test whether psychological control items used with adolescents in previous research by Barber (1996) fit the cross-cultural data for mothers of preschoolers. Data from fathers was not used because of limitations in the sample size for fathers in some cultures.

We tested Barber's 8-item model (see Table 5 in Barber, 1996, for specific items) to assess whether the factor structure was comparable across cultures. Invariance of factor loadings was tested by comparing an unconstrained model with one whose factor loadings were constrained to be equivalent across the three cultures. The significant chi-square difference 
$\left(\chi_{\mathrm{dif}}^{2}=26.97\left[d f_{\mathrm{dif}}=14\right], p<.02\right)$ indicated that these items did not relate to the latent construct in the same way across the three cultures.

\section{MATERNAL PSYCHOLOGICAL CONTROL MEASUREMENT MODEL}

To find a model that was comparable across cultures, we next considered the Barber (1996) items as well as the additional psychological control items from the larger item bank, augmented by early childhood professionals. The relationships between these items and internalizing and externalizing behaviors were also explored, and items that were linked to these constructs in at least one culture were retained for further analysis. The final set of psychological control items were grouped conceptually into four of the dimensions previously identified by Barber (1996), including personal attack, erratic emotional behavior, guilt induction, and love withdrawal (see Table 8-3). Scores for items in each dimension were summed, and mean scores were calculated for each dimension to simplify the model in further analyses.

A measurement model of the psychological control latent construct was tested to assess invariances of factor loadings among six groups (Chinese, Russian, and U.S.; boys and girls), using the previously mentioned dimensions (Table 8-4). The chi-square difference was nonsignificant $\left(\chi_{\text {dif }}^{2}=18.21\right.$ $\left[d f_{\text {dif }}=15\right], p<.25$ ), indicating that factor loadings were comparable (invariant) across the three cultures and across gender for this measurement model. Although the loading for erratic emotional behavior was relatively low

TABLE 8-3

Maternal Psychological Control Dimensions and Items Used in Cross-Cultural Reseach

\begin{tabular}{|c|c|}
\hline Dimension & Description \\
\hline Personal attack & $\begin{array}{l}\text { Brings up child's past mistakes when critizing him/her } \\
\text { Tells our child that his/her behavior was dumb or stupid }\end{array}$ \\
\hline $\begin{array}{l}\text { Erratic emotional } \\
\text { behavior }\end{array}$ & $\begin{array}{l}\text { Shows impatience with our child } \\
\text { Doesn't like to be bothered by our child } \\
\text { Changes moods when with our child }\end{array}$ \\
\hline Guilt induction & $\begin{array}{l}\text { Acts disappointed when our child misbehaves } \\
\text { Tells my child that he/she should be ashamed when he/she } \\
\text { misbehaves }\end{array}$ \\
\hline & $\begin{array}{l}\text { Tells my child that we get embarrassed when he/she does not } \\
\text { meet our expectations } \\
\text { Tells our child that he/she is not as good as other children }\end{array}$ \\
\hline Love withdrawal & $\begin{array}{l}\text { If our child hurts my feelings, stops talking to our child until he/ } \\
\text { she pleases me again } \\
\text { Am less friendly with our child when our child does not see } \\
\text { things my way }\end{array}$ \\
\hline
\end{tabular}


TABLE 8-4

Maternal Psychological Control Measurement Model

\begin{tabular}{|c|c|c|c|c|c|c|}
\hline & \multicolumn{2}{|c|}{ China } & \multicolumn{2}{|c|}{ Russia } & \multicolumn{2}{|c|}{ United States } \\
\hline & Boys & Girls & Boys & Girls & Boys & Girls \\
\hline $\begin{array}{l}\text { Personal attack } \\
\text { Erratic emotional behavior } \\
\text { Guilt induction } \\
\text { Love withdrawal }\end{array}$ & $\begin{array}{l}.72 \\
.41 \\
.77 \\
.65\end{array}$ & $\begin{array}{l}.67 \\
.40 \\
.70 \\
.51\end{array}$ & $\begin{array}{l}.58 \\
.40 \\
.74 \\
.51\end{array}$ & $\begin{array}{l}.62 \\
.40 \\
.82 \\
.54\end{array}$ & $\begin{array}{l}.66 \\
.36 \\
.82 \\
.52\end{array}$ & $\begin{array}{l}.70 \\
.37 \\
.72 \\
.70\end{array}$ \\
\hline
\end{tabular}

Note: $\chi^{2}(27)=46.72, \chi^{2} d f=1.73$, Goodness of Fit Index $=.97$, Tucker Lewis Index $=.94$, Comparative Fit Index $=.95$.

across cultures and gender, we decided to retain it in the model because conceptually it is considered an aspect of psychological control. ${ }^{1}$

\section{LATENT MEAN DIFFERENCES ACROSS CULTURES AND GENDERS FOR MATERNAL PSYCHOLOGICAL CONTROL}

With factor loadings of the psychological control construct invariant across cultures and gender, differences among the latent means could be estimated using the SEM procedure to minimize measurement error. Cole, Maxell, Arvey, and Salas (1993) recommended this procedure over multiple analysis of variance if there is a possibility of cultural bias. For the measurement model to be identified, the intercepts (means of the observed variables) were constrained to be identical across groups, and the latent mean for U.S. boys was constrained to be zero. The means of other groups that are relative to this group (0) are listed in Table 8-5. Because the latent means are relative to one another, the differences among the means remain the same, regardless of which group mean was constrained to be zero. As a consequence, differences also remain invariant when the measure is rescaled in different units. Mothers of Russian girls had the highest mean and U.S. girls' mothers had the lowest mean. Means for the Chinese mothers were in the middle of the distribution.

The latent mean differences between boys and girls within cultures (Table 8-5), and between China, Russia, and the United States within gender (Table 8-6), as shown by the letters in parentheses, were tested by comparing the chi-square change of the model when the means of the two groups were constrained to be equal as opposed to when they were

\footnotetext{
'Subsequent analyses testing the relationship between psychological control and child outcomes in the three cultures were performed. A model that included erratic emotional behavior as an indicator was estimated first. Estimating the original model without erratic emotional behavior did not alter the previous findings.
} 
TABLE 8-5

Latent Means and Difference for Maternal Psychological Control Between Boys and Girls Within Culture

\begin{tabular}{|c|c|c|c|}
\hline Culture & Group & Latent Mean & $\begin{array}{l}\text { Within-Culture } \\
\text { Difference Between } \\
\text { Boys and Girls }\end{array}$ \\
\hline United States & Boys $^{a}$ & 0 & $\begin{array}{l}(\mathrm{b} \& \mathrm{a}=0.06) \\
\chi_{\text {dif }}^{2}=1.03 p=0.31\end{array}$ \\
\hline China & $\begin{array}{l}\text { Girls } \\
\text { Boys }^{\mathrm{b}}\end{array}$ & $\begin{array}{l}-.06 \\
0.89\end{array}$ & $\begin{array}{l}(d \& c=0.05) \\
\chi_{\text {dit }}^{2}=0.40 p=0.53\end{array}$ \\
\hline Russia & $\begin{array}{l}\text { Girls }^{d} \\
\text { Boys }^{\theta} \\
\text { Girls }^{\prime}\end{array}$ & $\begin{array}{l}0.94 \\
1.24 \\
\\
1.25\end{array}$ & $\begin{array}{l}\text { (f \& e }=0.01) \\
\chi_{\text {dif }}^{2}=0.03 p=0.87\end{array}$ \\
\hline
\end{tabular}

Notes: " U.S. boys

${ }^{b}$ U.S. girls

'Chinese boys

a Chinese girls

- Russian boys

'Russian girls

unconstrained. A significant change of chi square relative to the change of one degree of freedom suggests a significant difference in the means.

Within each culture, the nonsignificant chi-square difference suggests that mothers' psychological control toward boys is the same as it is toward girls (Table 8-5). However, the level of psychological control varied across

TABLE 8-6

Latent Mean Differences for Maternal Psychological Control Across Cultures for Boys and Girls

\begin{tabular}{|c|c|c|c|}
\hline & United States & China & Russia \\
\hline United States & & $\begin{array}{l}(d \& b=1.00) \\
\chi^{2} \&=129.63 p=.00\end{array}$ & $\begin{array}{l}(f \& b=1.31) \\
\chi^{2}=158.59 p=.00\end{array}$ \\
\hline $\begin{array}{l}\text { China } \\
\text { Russia }\end{array}$ & $\begin{array}{l}(c \& a=0.89) \\
\chi_{\text {dif }}^{2}=116.64 p=.00 \\
(e \& a=1.24) \\
\chi_{\text {dif }}^{2}=132.19 p=.00\end{array}$ & $\begin{array}{l}(e \& c=0.35) \\
\chi_{d i f}^{2}=14.33 p=.00\end{array}$ & $\begin{array}{l}(f \& d=0.31) \\
\chi_{\text {dif }}^{2}=12.06 p=.00\end{array}$ \\
\hline
\end{tabular}

Notes: Girls above the diagonal: boys below the diagonal.

U.S. boys

U.S. girls

c Chinese boys

d Chinese girls

- Russian boys

$(0)$

$(-.06)$

$(0.89)$

(0.94).

${ }^{+}$Russian girls

(1.24). 
the three cultures, as indicated by the significant chi-square differences for boys and girls across cultural groups (Table 8-6).

\section{INTERNALIZING AND EXTERNALIZING MEASUREMENT MODEL}

The cross-cultural comparability of the internalizing and externalizing constructs was also tested using the chi-square differences between a constrained measurement model and an unconstrained one. The fit of the unconstrained model was acceptable $\left(\chi^{2}=315.89[\mathrm{df}=156], p<.00\right.$; Goodness of Fit Index $(\mathrm{GFI})=.90$; Comparative Fit Index $(\mathrm{CFI})=.92$; Tucker Lewis Index $(T L I)=.89)$. When all the factor loadings were constrained to be equivalent across cultures and gender, the chi square increased significantly from that of an unconstrained model $\left(\chi_{\text {dif }}^{2}=86.03\left[d f_{\text {dif }}=35\right], p<\right.$ .00 ), implying a variance in factor loadings across the six groups. Similar results were obtained even when substituting other possible internalizing and externalizing items from our item bank. Factor loadings of both constructs were found to be equivalent across gender in both the U.S. $\left(\chi_{\text {dif }}^{2}=\right.$ $\left.9.13\left[d f_{\text {dif }}=7\right], p<.24\right)$ and Chinese samples $\left(\chi_{\text {dif }}^{2}=10.73\left[d f_{\text {dif }}=7\right], p<.15\right)$.

Factor-loading equivalence was found across gender only for the externalizing construct in the Russian sample $\left(\chi_{\text {dif }}^{2}=5.55\left[d f_{\text {dif }}=4\right], p<.24\right)$. The factor loadings of externalizing were also found to be equivalent across the three male groups $\left(\chi_{\text {dif }}^{2}=7.08\left[d f_{\text {dif }}=8\right], p<.53\right)$. Because of the differences in factor loadings across some groups, the internalizing and externalizing measurement models were not comparable, and the latent means may vary with ways to identify the model. Thus, additional tests of latent mean differences were not pursued.

\section{PSYCHOLOGICAL CONTROL AND PRESCHOOLERS' INTERNALIZING AND EXTERNALIZING BEHAVIORS}

Finally, the link between mothers' psychological control and children's internalizing and externalizing behaviors was assessed using structural equation modeling. Because of the variance in factor loadings in the outcome variables, the full structural model was estimated using a multiple sample approach without constraining any parameters to be equivalent across the three samples and the six groups. This is similar to estimating different models for each group, but with one set of indexes of goodness of fit.

Two sets of analyses were performed. First, models were tested in the three cultures using boys' and girls' combined data (Table 8-7). Uncon- 
TABLE 8-7

Standardized Factor Loadings and Structural Coefficients for Confirmatory Factor Models of Psychological Control and Internalizing and Externalizing Behaviors Across Three Cultures

\begin{tabular}{lccc}
\hline & China & Russia & United States \\
\hline Psychological Control & & & \\
Personal attack & .70 & .60 & .68 \\
Erratic emotional behavior & .41 & .40 & .37 \\
Guilt induction & .72 & .75 & .75 \\
Love withdrawal & .58 & .52 & .60 \\
& & & \\
Externalizing & .88 & .73 & .75 \\
Aggressive when rough-housing & .59 & .58 & .61 \\
Blames others & .79 & .74 & .72 \\
Disturbs ongoing activities & .89 & .80 & .89 \\
Aggressive toward people & .82 & .78 & .73 \\
Gets into fights & & & \\
Internalizing & .51 & .54 & .66 \\
Acts unhappy & .33 & .61 & .56 \\
Says nobody likes him/her & .55 & .67 & .75 \\
Pouts and sulks & .70 & .46 & .55 \\
Appears lonely & & & \\
Structural Coefficients & .13 & $.30^{\star}$ & $.21^{*}$ \\
Psychological Control $\rightarrow$ Exter & .11 & .19 & $.22^{*}$ \\
Psychological Control $\rightarrow$ Inter &
\end{tabular}

Note: $\chi^{2}(195)=405.24,0^{2} / d f=2.08$, Goodness of Fit Index $=.91$, Tucker Lewis Index $=.90$, Comparative Fir Index = .92. ${ }^{*} p<.05$.

strained models were tested because the measurement models for internalizing and externalizing were not comparable across cultures. SEM revealed that for the U.S. data, psychological control was significantly related to both externalizing and internalizing behaviors. In China, no significant linkages were found. Psychological control was associated with externalizing behaviors only in the Russian sample. Model fit was acceptable $\left(\chi^{2}=354.35\right.$ $[d f=183], p<.001 ; \mathrm{GFI}=.92 ; \mathrm{CFI}=.93 ; \mathrm{TLI}=.91)$.

In the second set of analyses, models were tested for boys and girls in each of the three cultures (Table 8-8). For U.S. girls, psychological control was again related to both internalizing and externalizing behaviors. Psychological control was linked to internalizing behaviors for Chinese girls and externalizing behaviors for Russian girls. Model fit was adequate $\left(\chi^{2}=271.56\right.$ $[d f=180], p<.001 ; \mathrm{GFI}=.89 ; \mathrm{CFI}=.93 ; \mathrm{TLI}=.91$ ).

No associations existed between psychological control and internalizing or externalizing behaviors for U.S. boys. Psychological control was related with externalizing behaviors for Chinese boys and with both externalizing and internalizing behaviors for Russian boys. Fit was adequate 
TABLE 8-8

Standardized Factor Loadings and Structural Coefficients for Confirmatory Factor Models of Psychological Control and Internalizing and Externalizing Behaviors Across Three Cultures and Gender

\begin{tabular}{|c|c|c|c|c|c|c|}
\hline & \multicolumn{2}{|c|}{ China } & \multicolumn{2}{|c|}{ Russia } & \multicolumn{2}{|c|}{ United States } \\
\hline & Boys & Girls & Boys & Girls & Boys & Girls \\
\hline $\begin{array}{l}\text { Psychological Control } \\
\text { Personal attack } \\
\text { Erratic emotional behavior } \\
\text { Guilt induction } \\
\text { Love withdrawal }\end{array}$ & $\begin{array}{l}.71 \\
.44 \\
.76 \\
.66\end{array}$ & $\begin{array}{l}.75 \\
.39 \\
.51 \\
.65\end{array}$ & $\begin{array}{l}.55 \\
.42 \\
.69 \\
.51\end{array}$ & $\begin{array}{l}.68 \\
.39 \\
.76 \\
.54\end{array}$ & $\begin{array}{l}.65 \\
.39 \\
.81 \\
.53\end{array}$ & $\begin{array}{l}.74 \\
.35 \\
.67 \\
.67\end{array}$ \\
\hline $\begin{array}{l}\text { Externalizing } \\
\text { Aggressive when rough-housing } \\
\text { Blames others } \\
\text { Disturbs ongoing activities } \\
\text { Aggressive toward people } \\
\text { Gets into fights }\end{array}$ & $\begin{array}{l}.87 \\
.64 \\
.81 \\
.91 \\
.81\end{array}$ & $\begin{array}{l}.90 \\
.48 \\
.66 \\
.76 \\
.76\end{array}$ & $\begin{array}{l}.79 \\
.46 \\
.65 \\
.84 \\
.71\end{array}$ & $\begin{array}{l}.69 \\
.54 \\
.80 \\
.84 \\
.81\end{array}$ & $\begin{array}{l}.72 \\
.56 \\
.66 \\
.93 \\
.74\end{array}$ & $\begin{array}{l}.79 \\
.64 \\
.82 \\
.85 \\
.76\end{array}$ \\
\hline $\begin{array}{l}\text { Internalizing } \\
\text { Acts unhappy } \\
\text { Says nobody likes him/her } \\
\text { Pouts and sulks } \\
\text { Appears lonely }\end{array}$ & $\begin{array}{l}.48 \\
.19 \\
.62 \\
.69\end{array}$ & $\begin{array}{l}.41 \\
.52 \\
.58 \\
.60\end{array}$ & $\begin{array}{l}.70 \\
.31 \\
.59 \\
.60\end{array}$ & $\begin{array}{l}.39 \\
.84 \\
.70 \\
.27\end{array}$ & $\begin{array}{l}.86 \\
.42 \\
.64 \\
.66\end{array}$ & $\begin{array}{l}.50 \\
.66 \\
.79 \\
.54\end{array}$ \\
\hline $\begin{array}{l}\text { Structural Coefficients } \\
\text { Psychological Control } \rightarrow \text { Exter } \\
\text { Psychological Control } \rightarrow \text { Inter }\end{array}$ & $\begin{array}{c}.28^{*} \\
-.16\end{array}$ & $\begin{array}{c}-.08 \\
.51^{\star}\end{array}$ & $\begin{array}{l}.34^{*} \\
.33^{*}\end{array}$ & $\begin{array}{l}.31^{\star} \\
.17\end{array}$ & $\begin{array}{r}.04 \\
-.02\end{array}$ & $\begin{array}{l}.26^{\star} \\
.33^{*}\end{array}$ \\
\hline
\end{tabular}

Note: For boys: $\chi^{2}(180)=277.16,0^{2} d f=1.54$, Goodness of Fit Index $=.89$, Tucker Lewis Index $=.90$, Comparative Fit Index $=.92$.

For girls: $\chi^{2}(180)=271.56,0^{2} d f=1.51$, Goodness of Fit Index $=.89$, Tucker Lewis Index $=.91$, Comparative Fit Index $=.93 .{ }^{*} p<.05$.

for this model $\left(\chi^{2}=277.16[d f=180], p<.001 ;\right.$ GFI $=.89$; CFI $=.92$; TLI $=.90)$.

\section{CONNECTIONS WITH PREVIOUS RESEARCH, LIMITATIONS, AND FUTURE DIRECTIONS}

The findings of this research are limited to maternal perceptions of psychological control and teachers' perceptions of children's externalizing and internalizing behavior in specific geographic locations within the three cultures and may be prone to type I error because of the number of correlation analyses. In addition, data is cross-sectional, based on mothers' self-reports of psychological control, and the research included measures of the dependent variable that may be considered limited in scope. Nevertheless, this research provides a starting point for an initial understanding of the relationships 
between psychological control and preschool children's internalizing and externalizing behaviors in three cultures.

The results indicated that the psychological control factor structure used in previous research with adolescents in the United States was not comparable for samples of Chinese, Russian, and U.S. preschoolers; however, after including items developed by early childhood professionals, it was possible to identify a factor structure for the maternal psychological control construct that was comparable across cultures. Triandis (1994) has noted that if in factor analysis the same items empirically cluster in each culture, this is an indication that in those cultures the latent construct may have the same meaning.

When comparing the latent means, within each of the three cultures mothers' use of psychological control with boys did not differ significantly from that of girls. However, when differences across cultures and genders were considered separately, there were significant differences among the latent means (U.S. mothers scored lowest and Russian mothers scored highest for both boys and girls). Psychological control may be more ingrained in Russian culture (Bronfenbrenner, 1970) and used more often by Chinese mothers because of its link to Confucian ideology (Ho, 1986). As a consequence, the use of psychological control or its components may be viewed as an effective means of obtaining parental goals for socialization of children in Russia and China. Thus, parents in these cultures may be inclined to use psychological control more often, which might explain why their latent means are higher than those in the United States.

Triandis (1994) provided another possible explanation for crosscultural differences, noting that response sets to questions may vary across cultures. In some cultures people might mark moderate responses, whereas in other cultures individuals may mark extreme responses. As a consequence, parent measures used in different cultures may not reflect a common metric, because of differential reference points or response sets, reflecting societal norms. For example, in China, as in most Confucian cultures, there is the doctrine of the mean (Zhong Yong Zhi Dao) which promotes the avoidance of extremes. It may be possible that even though psychological control is a common parenting strategy in China, Chinese parents were more conservative than Russian parents in rating themselves because they felt it was improper to highlight their own behavior relative to societal norms. Further research is needed to address this issue.

A final purpose of this research was to assess whether or not the linkages between mothers' use of psychological control and preschool children's internalizing and externalizing behaviors were consistent with the literature and apply cross-culturally. Our results with preschool children partially support the findings of previous research conducted with adolescents and older schoolage children in the United States (chapter 2, this volume). 
Specifically, results obtained with our sample of preschool children (boys and girls combined) in the United States were consistent with previous research findings in that preschoolers exposed to higher levels of maternal psychological control were perceived by teachers as displaying more internalizing and externalizing behaviors. This finding is also consistent with the cross-cultural evidence for psychological control of adolescents presented in chapter 2 of this volume, two of which cultures (Gaza and India) have authoritarian and collectivist characteristics. Findings from the other two samples in this study were less clear. In the Chinese sample, when male and female data were analyzed together, no linkages emerged between mothers' use of psychological control and children's internalizing and externalizing behaviors. When analyzing the combined male and female Russian samples, mothers' use of psychological control was related only to externalizing behaviors (a finding that was consistent with our earlier work from the same Russian sample; Hart, Nelson, et al., 1998). However, when we examined gender-differentiated linkages between maternal psychological control and child problems, a more refined, and complex, pattern of effects emerged. Specifically, psychological control was positively related to internalizing and externalizing for U.S. girls and Russian boys. The construct was positively associated with externalizing only for Russian girls and Chinese boys and with internalizing for Chinese girls.

The cross-cultural study of psychological control and its outcomes is a relatively new area of investigation. Although there has been some initial work with samples of adolescents of varied ethnicity in the United States (Bean, 1997; Mason et al., 1996) as well as in other cultures (chapter 2, this volume), none of these have separated samples by child gender when determining levels of parental psychological control. In addition, studies other than our own have not differentiated the effects of parental psychological control on boys versus girls. In general, the systematic study of the linkages between parenting and gender issues is more well-developed in western societies (see Hart et al., 1997; Russell \& Russell, 1992; Russell et al., 1998; for reviews), but in China and Russia is relatively unexplored. Future research should continue to investigate the relationships between psychological control and preschool children's outcomes, taking into account both culture and gender.

In the future, researchers might investigate temperamental, social cognitive, or emotional mechanisms linking psychological control and preschooler's internalizing and externalizing behaviors (e.g., Hart, Nelson, et al., 2000). For example, research on parenting that is coercive and characterized by behavioral overcontrol indicates that children who are raised in this manner may exhibit disregulated emotion and be less likely to successfully encode social cues and consider appropriate consequences for their actions, which, in turn, may be related to aggression (e.g., Dodge, Bates, \& Pettit, 
1990; Dodge, Pettit, Bates, \& Valente, 1995; Hart, Ladd, \& Burleson, 1990). Because authoritarian parenting has also been linked to internalizing disorders (see Hart et al., 1997, for a review), and parental use of psychological control has been associated with both internalizing and externalizing, similar social-cognitive and emotional processes may be at work. Future research is needed to explore this possibility (see chapters 4 and 5 , this volume, for efforts to account for child characteristics in the study of parental psychological control).

In generalizing findings, we must recognize the diversity of individuals living in China, the United States, and Russia. Cultures do not necessarily have "unitary orientations" (Yau \& Smetana, 1996), and patterns of childrearing may vary within cultures because of ethnic differences (Olson \& Matskovsky, 1994). Stevenson-Hinde (1998) also reminded us that numerous differences may exist between rural and urban areas within a country, and as a consequence, "variation within countries may be as large as that between countries" (p. 699). Although these findings may apply to the sampled mothers in Beijing, Voronezh, and Provo-Orem, they may not be applicable to all ethnic groups or individuals in these three countries.

To improve the validity of cross-cultural findings, future research needs to include a multimethod approach (Triandis, 1994), possibly using ethnographic and qualitative methodologies to discover more precise cultural nuances associated with psychological control and its relationship to preschoolers' internalizing and externalizing in these cultures.

In sum, this research was a beginning foray into studying linkages between maternal psychological control and preschoolers' outcomes in different cultures. Links were found between psychological control and child outcomes in all three cultures; however, this research also raises new questions and avenues of study regarding child gender and its linkages to psychological control in non-Western settings that should prove to be a fruitful area of future inquiry.

\section{REFERENCES}

Alessandri, S. M., \& Lewis, M. (1993). Parental evaluation and its relations to shame and pride in young children. Sex Roles, 29, 335-343.

Arbuckle, J. (1997). Amos users' guide: Version 3.6. Chicago: Smallwaters.

Barber, B. K. (1996). Parental psychological control: Revisiting a neglected construct. Child Development, 67, 3296-3319.

Barber, B. K. (1997a). Introduction: Adolescent socialization in context-Connection, regulation, and autonomy in multiple contexts. Journal of Adolescent Research, 12, 173-177. 
Barber, B. K. (1997b). Introduction: Adolescent socialization in context-The role of connection, regulation, and autonomy in the family. Joumal of Adolescent Research, 12, 5-11.

Barber, B. K., \& Olsen, J. A. (1997). Socialization in context: Connection, regulation, and autonomy in the family, school, and neighborhood, and with peers. Journal of Adolescent Research, 12, 287-315.

Barber, B. K., Olsen, J. A., \& Shagle, S. C. (1994). Associations between parental psychological and behavior control and youth internalized and externalized behaviors. Child Development, 65, 1120-1136.

Baumrind, D. (1966). Effects of authoritative control on child behavior. Child Development, 37, 887-907.

Bean, R. A. (1997). Academic grades, delinquency, and depression among ethnically diverse youth: The influence of parental connection, regulation, and psychological control. Unpublished doctoral dissertation, Brigham Young University, Provo, Utah.

Berry, J. W. (1989). Imposed etics-emics-derived etics: The operationalization of a compelling idea. International Journal of Psychology, 24, 721-735.

Bond, M. H. (1991). Beyond the Chinese face: Insights from psychology. Oxford: Oxford University Press.

Bronfenbrenner, U. (1970). Two worlds of childhood: U.S. and U.S.S.R. New York: Russell Sage Foundation.

Chen, X., Dong, Q., \& Zhou, H. (1997). Authoritative and authoritarian parenting practices and social and school performance in Chinese children. International Journal of Behavioral Development, 21, 855-873.

Chen, X., Rubin, K. H., Li, B., \& Li, D. (1996, August). Adolescent outcomes of social functioning in Chinese children. XXVI International Congress of Psychology, Montreal, Quebec, Canada.

Cole, D. A., Maxwell, S. E., Arvey, R., \& Salas, E. (1993). Multivariate group comparisons of variable systems: MANOVA and structural equation modeling. Psychological Bulletin, 114, 174-184.

Crockenberg, S., \& Litman, C. (1990). Autonomy as competence in 2-year-olds: Maternal correlates of child defiance, compliance, and self-assertion. Developmental Psychology, 26, 961-971.

Darling, N., \& Steinberg, L. (1993). Parenting style as context: An integrative model. Psychological Bulletin, 113, 487-496.

Dodge, K. A., Pettit, G. S., \& Bates, J. E. (1990). Mechanisms in the cycle of violence. Science, 250, 1678-1683.

Dodge, K. A., Pettit, G. S., Bates, J. E., \& Valente, E. (1995). Social informationprocessing patterns partially mediate the effect of early physical abuse on later conduct problems. Journal of Abnormal Psychology, 104, 632-643.

Eccles, J. S., Early, D., Frasier, K., Belansky, E., \& McCarthy, K. (1997). The relation of connection, regulation, and support for autonomy to adolescents' functioning. Journal of Adolescent Research, 12, 245-262. 
Eisenberg, N., \& Murphy, B. (1995). Parenting and children's moral development. In M. H Bornstein (Ed.), Handbook of parenting: Vol. 4. Applied and practical parenting (pp. 227-258). Mahwah, NJ: Erlbaum.

Fung, H. (1999). Becoming a moral child: The socialization of shame among young Chinese children. Manuscript submitted for publication.

Garcia Coll, C. T., Meyer, E. C., \& Brillon, L. (1995). Ethnic and minority parenting. In M. H. Bornstein (Ed.), Handbook of parenting: Vol. 2. Biology and ecology of parenting (pp. 189-209). Mahwah, NJ: Erlbaum.

Gorman, J. C. (1998). Parenting attitudes and practices of immigrant Chinese mothers of adolescents. Family Relations, 47, 73-80.

Gottman, J. M., Katz, L. F., \& Hooven, C. (1997). Meta-emotion: How families communicate emotionally. Mahwah, NJ: Erlbaum.

Gray, M. R., \& Steinberg, L. (1999). Unpacking authoritative parenting: Reassessing a multidimensional construct. Journal of Marriage and the Family, 61, 574-587.

Gresham, F. M., \& Elliott, S. N. (1990). Social skills rating system manual. Circle Pines, MN: American Guidance Service.

Grotpeter, J. K. (1997). Relational aggression, overt aggression, and family relationships. Unpublished doctoral dissertation, University of Illinois at UrbanaChampaign.

Hart, C. H., Ladd, G. W., \& Burleson, B. R. (1990). Children's expectations of the outcomes of social strategies: Relations with sociometric status and maternal disciplinary styles. Child Development, 61, 127-137.

Hart, C. H., Nelson, D., Robinson, C. C., Olsen, S. F., \& McNeilly-Choque, M. K. (1998). Overt and relational aggression in Russian nursery-schoolage children: Parenting style and marital linkages. Developmental Psychology, $34,687-697$.

Hart, C. H., Nelson, D. A., Robinson, C. C., Olsen, S. F., McNeilly-Choque, M. K., Porter, C. L., \& McKee, T. R. (2000). Russian parenting styles and family processes: Linkages with subtypes of victimization and aggression. In $\mathrm{K}$. A. Kerns, J. M. Contreras, \& A. M. Neal-Barnett (Eds.), Family and peers: Linking two social worlds (pp. 47-84). Westport, CT: Praeger.

Hart, C. H., Newell, L. D., \& Olsen, S. F. (in press). Parenting skills and social/ communicative competence in childhood. In J. O. Greene \& B. R. Burleson (Eds.), Handbook of communication and social interaction skill. Mahwah, NJ: Erlbaum.

Hart, C. H., Olsen, S. F., Robinson, C. C., \& Mandleco, B. L. (1997). The development of social and communicative competence in childhood: Review and a model of personal, familial, and extra familial processes. In B. R. Burleson (Ed.), Communication yearbook (Vol. 20, pp. 305-373). Thousand Oaks, CA: Sage.

Hart, C. H., Yang, C., Nelson, L. J., Robinson, C. C., Olsen, J. A., Nelson, D. A., Porter, C. L., Jin, S., Olsen, S. F., \& Wu, P. (2000). Peer acceptance in early childhood and subtypes of socially withdrawn behavior in China, Russia, and the United States. International Journal of Behavioral Development, 24, 73-81. 
Ho, D. Y. F. (1986). Chinese patterns of socialization: A critical review. In M. H. Bond (Ed.), The psychology of the Chinese people (pp. 1-37). Hong Kong: Oxford University Press.

Ho, D. Y. F. (1996). Filial piety and its psychological consequences. In M. H. Bond (Ed.), The handbook of Chinese psychology (pp. 155-165). Hong Kong: Oxford University Press.

Hoffman, M. L. (1983). Affective and cognitive processes in moral internalization. In E. T. Higgins, D. N. Ruble, \& W. W. Hartup (Eds.), Social cognition and social development (pp. 236-274). Cambridge: Cambridge University Press.

Holden, G. W. (1997). Parents and the dynamics of child rearing. Boulder, CO: Westview Press.

Little, T. D. (1997). Mean and covariance structures (MACS) analyses of crosscultural data: Practical and theoretical issues. Multivariate Behavioral Research, $32,53-76$.

Maccoby, E. E., \& Martin, J. A. (1983). Socialization in the context of the family: Parent-child interaction. In P. H. Mussen (Series Ed.) \& E. M. Hetherington (Vol. Ed.), Handbook of child psychology: Vol. 4. Socialization, personality, and social development (pp. 1-102). New York: Wiley.

Marenko (1937). The collective family: A handbook for Russian parents (R. Daglish, Trans.). New York: Anchor Books.

Mason, C. A., Cauce, A. M., Gonzales, N., \& Hiraga, Y. (1996). Neither too sweet nor too sour: Problem peers, maternal control, and problem behavior in African American adolescents. Child Development, 67, 2115-2130.

McNeilly-Choque, M. K., Hart, C. H., Robinson, C. C., Nelson, L. J., \& Olsen, S. F. (1996). Overt and relational aggression on the playground: Correspondence among different informants. Journal of Research in Childhood Education, 11, 4767.

Miller, P. J., Wiley, A. R., Fung, H., \& Liang, C. (1997). Personal storytelling as a medium of socialization in Chinese and American families. Child Development, 68, 557-568.

Mills, R. S. L., \& Rubin, K. H. (1998). Are behavioural and psychological control both differentially associated with childhood aggression and social withdrawal? Canadian Journal of Behavioural Sciences, 30, 132-136.

Nelson, D. A. (1997, April). Family relationships of relationally and overtly victimized children. Paper presented at the biennial conference of the Society for Research in Child Development, Washington, DC.

Nelson, L. J., Hart, C. H., Robinson, C., \& Olsen, S. F. (1997, April). Relations between three subtypes of withdrawn behavior and peer acceptance in preschool children: A multi-method perspective. Paper presented at the biennial conference of the Society for Research in Child Development, Washington, DC.

Olsen, S. F., Wells, M. E. W., Hart, C. H., \& Robinson, C. C. (2000). Parental psychological control and preschool children's intemalizing and externalizing behavior. Manuscript in preparation. 
Olson, D. H., \& Matskovsky, M. S. (1994). Soviet and American families: A comparative overview. In J. W. Maddock, M. J. Hogan, A. I. Antonov, \& M. S. Matskovsky (Eds.), Families before and after Perestroika: Russian and U.S. perspectives (pp. 9-35). New York: Guilford Press.

Pallock, L., \& Lamborn, S. (1997, April). Russian teens perceptions of parents and self. Paper presented at the biennial conference of the Society for Research in Child Development, Washington, DC.

Putallaz, M., \& Heflin, A. H. (1990). Parent-child interaction. In S. R. Asher \& J. D. Coie (Eds.), Peer rejection in childhood: Origins, consequences, and intervention (pp. 274-305). Cambridge: Cambridge University Press.

Rollins, B. C., \& Thomas, D. L. (1979). Parental support, power, and control techniques in the socialization of children. In W. R. Burr, R. Hill, F. I. Nye, \& I. L. Reiss (Eds.), Contemporary theories about the family: Vol. 1. Researchbased theories (pp. 317-364). New York: Free Press.

Rubin, K. H., Bukowski, W., \& Parker, J. G. (1998). Peer interactions, relationships, and groups. In Handbook of child psychology: Vol. 3. Social, emotional, personality development (pp. 619-700). Hillsdale, NJ: Erlbaum.

Rubin, K. H., \& Coplan, R. J., Nelson, L. J., Cheah, C., \& Lagace-Seguin, D. G. (1999). Peer relationships in childhood. In M. A. Bornstein \& M. E. Lamb (Eds.), Developmental psychology: An advanced textbook (pp. 451-502). Hillsdale, NJ: Erlbaum.

Rubin, K. H., Nelson, L. J., Hastings, P., \& Asendorpf, J. (1999). The transaction between parents' perceptions of their children's shyness and their parenting styles. International Journal of Behavioral Development, 23, 937-957.

Rubin, K. H., Stewart, S. L., \& Chen, X. (1995). Parent of aggressive and withdrawn children. In M. Bornstein (Ed.), Handbook of parenting: Vol. 1. Children and parenting (pp. 255-284). Mahwah, NJ: Erlbaum.

Russell, A., Aloa, V., Feder, T., Glover, A., Miller, H., \& Palmer, G. (1998). Sexbased differences in parenting styles in a sample with preschool children. Australian Journal of Psychology, 50, 89-99.

Russell, A., \& Russell, G. (1992). The socialization of Australian boys and girls in middle childhood for independence and achievement. In J. L. Roopnarine \& D. B. Carter (Eds.), Parent-child socialization in diverse cultures: Annual advances in applied development psychology (Vol. 5, pp. 53-74). Norwood, NJ: Ablex.

Segal, M. H., Lonner, W. J., \& Berry, J. W. (1998). Cross-cultural psychology as a scholarly discipline. American Psychologist, 53, 1101-1110.

Shulman, S., Collins, W. A., \& Dital, M. (1993). Parent-child relationships and peer-perceived competence during middle childhood and preadolescence in Israel. Journal of Early Adolescence, 13, 204-218.

Siqueland, L., Kendall, P. C., \& Steinberg, L. (1996). Anxiety in children: Family environments and family interaction. Journal of Clinical Child Psychology, $25,225-237$. 
Stark, K. D., Humphrey, L. L., Crook, K., \& Lewis, K. (1990). Perceived family environments of depressed and anxious children: Child's and maternal figure's perspectives. Journal of Abnormal Child Psychology, 18, 527-547.

Steinberg, L. (1990). Autonomy, conflict, and harmony in the family relationship. In S. S. Feldman \& G. R. Elliott (Eds.), At the threshold: The developing adolescent (pp. 255-276). Cambridge, MA: Harvard University Press.

Steinberg, L., Dornbusch, S. M., \& Brown, B. B. (1992). Ethnic differences in adolescent achievement: An ecological perspective. American Psychologist, $47,723-729$.

Steinberg, L., Elmen, J. D., \& Mounts, N. S. (1989). Authoritative parenting, psychosocial maturity, and academic success among adolescents. Child Development, $60,1424-1436$.

Steinberg, L., Mounts, N. S., Lamborn, S. D., \& Dornbusch, S. M. (1991). Authoritative parenting and adolescent adjustment across varied ecological niches. Journal of Research on Adolescence, 1, 19-36.

Stevenson, H. W., Chen, C., \& Lee, S. (1992). Chinese families. In J. L Roopnarine \& D. B. Carter (Vol. Eds.), I. E. Sigel (Series Ed.), Parent-child socialization in diverse cultures: Annual advances in applied developmental psychology (Vol. 5, pp. 17-33). Norwood, NJ: Ablex.

Stevenson-Hinde, J. (1998). Parenting in different cultures: Time to focus. Developmental Psychology, 34, 698-700.

Subbotskii, E. V. (1992). Moral socialization of the child in the Soviet Union from birth to age seven. In J. L. Roopnarine \& D. B. Carter (Eds.), Parent-child socialization in diverse cultures (pp. 89-105). Norwood, NJ: Ablex.

Triandis, H. C. (1994). Culture and social behavior. New York: McGraw-Hill.

Wells, M. E. W. (1998). Psychological control and internalizing and externalizing behavior in early childhood. Unpublished master's thesis, Brigham Young University.

Widaman, K. F., \& Reise, S. P. (1997). Exploring the measurement invariance of psychological instruments: Applications in the substance use domain. In K. J. Bryant, M. Windle, \& S. G. West (Eds.), The science of prevention: Methodological advances from alcohol and substance abuse research (pp. 281-324). Washington, DC: American Psychological Association.

Wilson, R. W. (1970). Learning to be Chinese. Cambridge: MIT Press.

Wilson, R. W. (1981). Moral behavior in Chinese society: A theoretical perspective. In R. W. Wilson, S. L. Greenblatt, \& A. A. Wilson (Eds.), Moral behavior in Chinese society (pp. 117-136). New York: Praeger.

Wu, D. Y. H. (1985). Child training in Chinese culture. In W. Tseng \& D. Y. H. Wu (Eds.), Chinese culture and mental health (pp. 113-134). New York: Academic Press.

Wu, D. Y. H. (1996). Chinese childhood socialization. In M. H. Bond (Ed.), The handbook of Chinese psychology (pp. 143-154). New York: Oxford University Press. 
Wu, D. Y. H. (1997). Parental control: Psychocultural interpretations of Chinese patterns of socialization. In S. Lau (Ed.), Growing up the Chinese way: Chinese child and adolescent development (pp. 1-28). Hong Kong: Chinese University Press.

Wu, P., Robinson, C. C., Hart, C. H., Yang, C., Hart, C. H., Olsen, S. F., \& Jin, S., Wo, J., \& Wu, X. (2000). Understanding Chinese parenting of preschool children through cultural notions. Manuscript submitted for publication.

Yau, J., \& Smetana, J. G. (1996). Adolescent-parent conflict among Chinese adolescents in Hong Kong. Child Development, 67, 1262-1275. 